\title{
ENERGY STORAGE IN BATTERY FOR REMOTE AREA USING WIND DFIG GENERATION
}

\author{
Dr. Arul Prasanna M, \\ Department of Electrical and Electronics and Engineering, \\ PSNA College of Engineering and Technology, \\ Dindigul, Tamil Nadu, India \\ arulprasanna@psnacet.edu.in \\ Dr. Soundar Rajan P, \\ Department of Electrical and Electronics and Engineering, \\ PSNA College of Engineering and Technology, \\ Dindigul, Tamil Nadu, India \\ soundar_psr@psnacet.edu.in \\ Praveenraj G, \\ Department of Electrical and Electronics and Engineering, \\ PSNA College of Engineering and Technology, \\ Dindigul, Tamil Nadu, India \\ praveenrajmw@psnacet.edu.in
}

\begin{abstract}
In this study, an efficient system is designed to maintain the Direct Current (DC) link voltage and improving voltage gain at remote side inverter using Hysteresis Controller (HC). The energy from wind is fed to the Remote Area Power Systems (RAPS). There is a need to control the changing frequency due to environmental changes in order to sustain the voltage at inverter side. It is achieved by the $\mathrm{HC}$ controller that provides control signals to inverter switches. The two-levels of Energy Storage System (ESS) are used as battery at source side and transformer at load side. The battery stores energy from the power converter stage through bi-directional converter where the energy flows in both forward and reverse direction. The frequency regulation based RAPS system is implemented using MATLAB/Simulink tool.
\end{abstract}

Keywords: Hysteresis controller, energy storage system, boost and bidirectional converter, RAPS.

\section{INTRODUCTION}

One of the major problems in the rural areas and villages is the lack of energy. The companies working in distribution and electrical sectors are having the challenge to overcome this energy poverty [1-2]. Due to technical and economical reasons, $22 \%$ of people in the world are living with high problematic connection of energy. In the rural areas, the people uses diesel generator which pollutes the environment and also the fuel cost is high [2-4].

The reduction in electrification can be possible with the help of renewable energy sources such as solar, water and wind. However, the renewable energy sources are not able to transmit when compared to previous and existing energy generations such as hydro and thermal [5]. Due to the penetration level increment of renewable sources, the conventional generators meet the load requirement in remote areas [6-7]. The RAPS is the process of power transmission to certain load in the rural areas and remote sides.

The architecture of RAPS consists of source energy, step up transformer, bus and certain load such as generator, grid applications, and nano grids [8-10]. 
For the wind energy generation and frequency regulation, the Doubly Fed Induction Generator (DFIG) is used in [11]. The permanent magnet synchronous generator is suitable for generating wind energy in rural areas where the wind availability is more [12].

A solar and wind hybrid system is discussed in [13] to provide electrical power to the east coast zone of India. A hybrid microgrid system is utilized to distribute the power to the loads. The micro-grid and nano-grid applications utilize renewable energy sources. The source of energy can be transferred to DC load and AC loads simultaneously with the help of power converters [14]. For rural electrification, photo voltaic based system is discussed in [15]. It combines multiple energy sources to provide power to the loads with the help of bifurcation process.

In this study, DFIG based RAPS is designed with the help of HC to maintain the voltage. Section 2 discusses about various components used for this system. Section 3 shows the simulations results of the system from MATLAB/simulink. The conclusion is given in the final section.

\section{METHODS AND MATERIALS}

The system consists of wind energy generator, uncontrolled rectifier, power converter, ESS, and inverter. HC is used to control the voltage source inverter at RAPS system. The generated energy from wind generator is three phase AC voltage and it is fed into the rectification process. The power diodes in the uncontrolled rectifier are act as switches. The rectified energy is fed through the power conversion stage where the boost converter regulates the rectified energy (DC) and then the excess energy from wind is stored in the battery using the bidirectional converter. The DC link voltage is maintained and fed to voltage source inverter to improve the energy conversion for RAPS system. The block diagram of DFIG based RAPS is shown in Fig. 1.

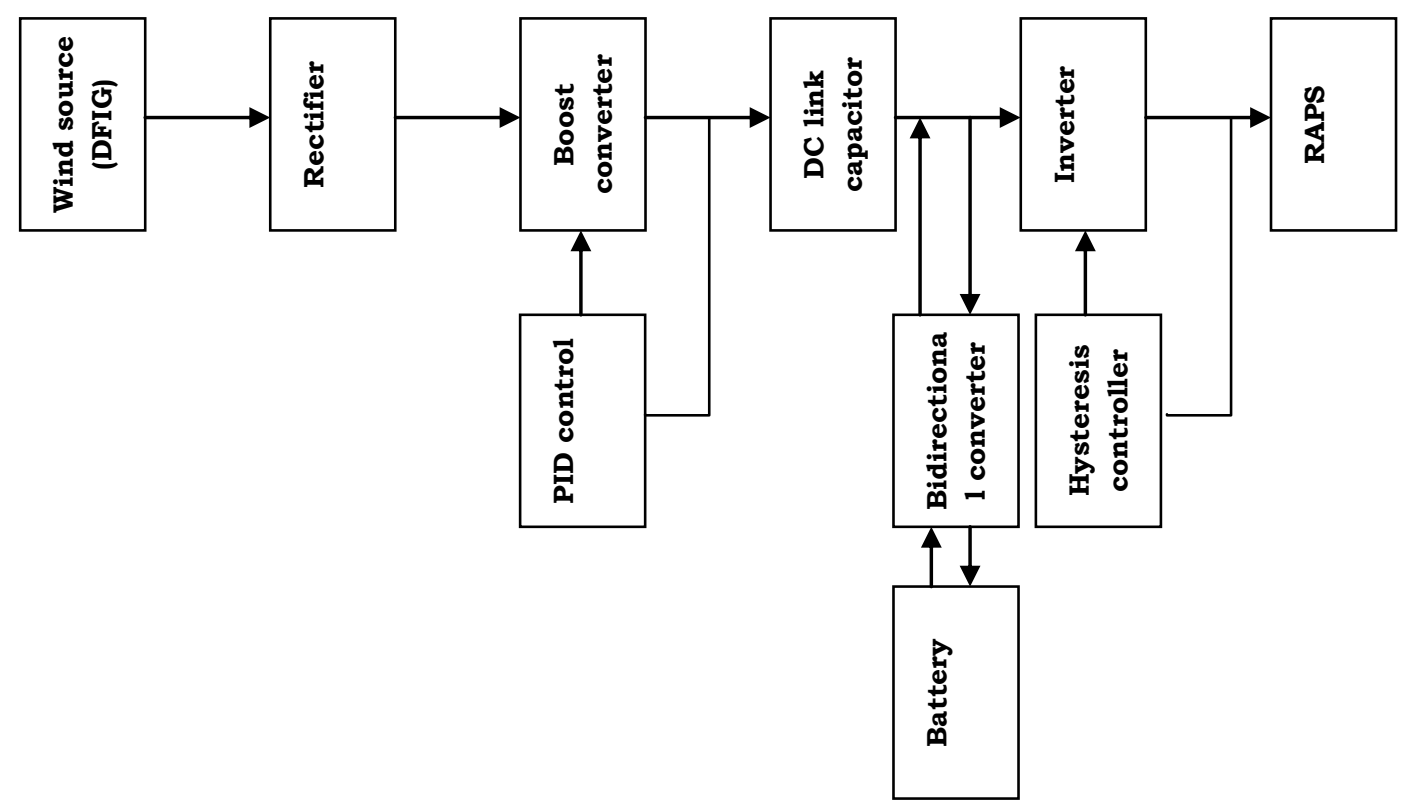

Fig. 1 System block diagram 
The wind energy generation is one of the renewable energy systems. The energy generation system consists of generator, turbine, rotor, motor and rotor hub as well as blades. In this system the efficient power is generated using DFIG. The DFIG based RAPS has two power converters such boost converter and bidirectional converter. In the first stage, the rectified energy is passed through boost converter to enhance the voltage gain. In the next stage, a bidirectional converter is used for storing the energy in battery using EES when the supply exceeds the power of load demand and the ESS discharges its energy during the lack of energy generation due to wind speed, environmental affects etc.

In this study, $\mathrm{HC}$ is used in the power conversion stages controllers to control the process. Normally, controllers are used to feedback system for system stability. Initially, the rectified energy is fed to boost converter to maintain DC link voltage. The PID controller is used to control the converter to maintain the DC link voltage as well as to provide desired output to the system. The ESS system has battery to store the energy supply using bidirectional converter which provides power flow in both directions. This stored energy is used to compensate the supplied energy to RAPS system during the reduction of power and frequencies. The bidirectional converter controls the energy conversion between ESS and the system.

Finally, the DC link voltage is given to the voltage source inverter for converting the DC into AC voltage. The inverters improve the power using switches and their gate pulses. This is last stage of RAPS. The HC is used to control the voltage source converter using the voltage and current as feedback. The block diagram of HC design is shown in Fig. 2. The output of RAPS can be connected to any loads such as mechanical reserve transformer, nano grid and substations.

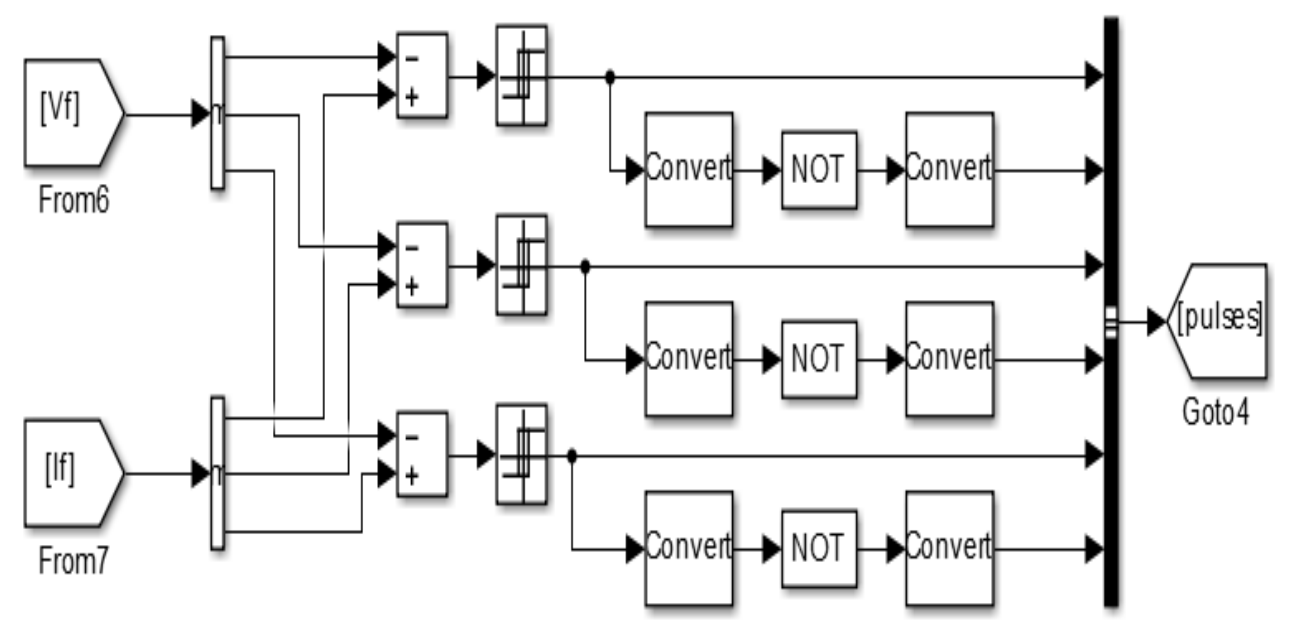

Fig. 2 HC design

\section{RESULTS AND DISCUSSION}

The DFIG energy generation system for RAPS is implemented with energy storage system using bidirectional converter. The simulink model is shown in Fig. 3. 


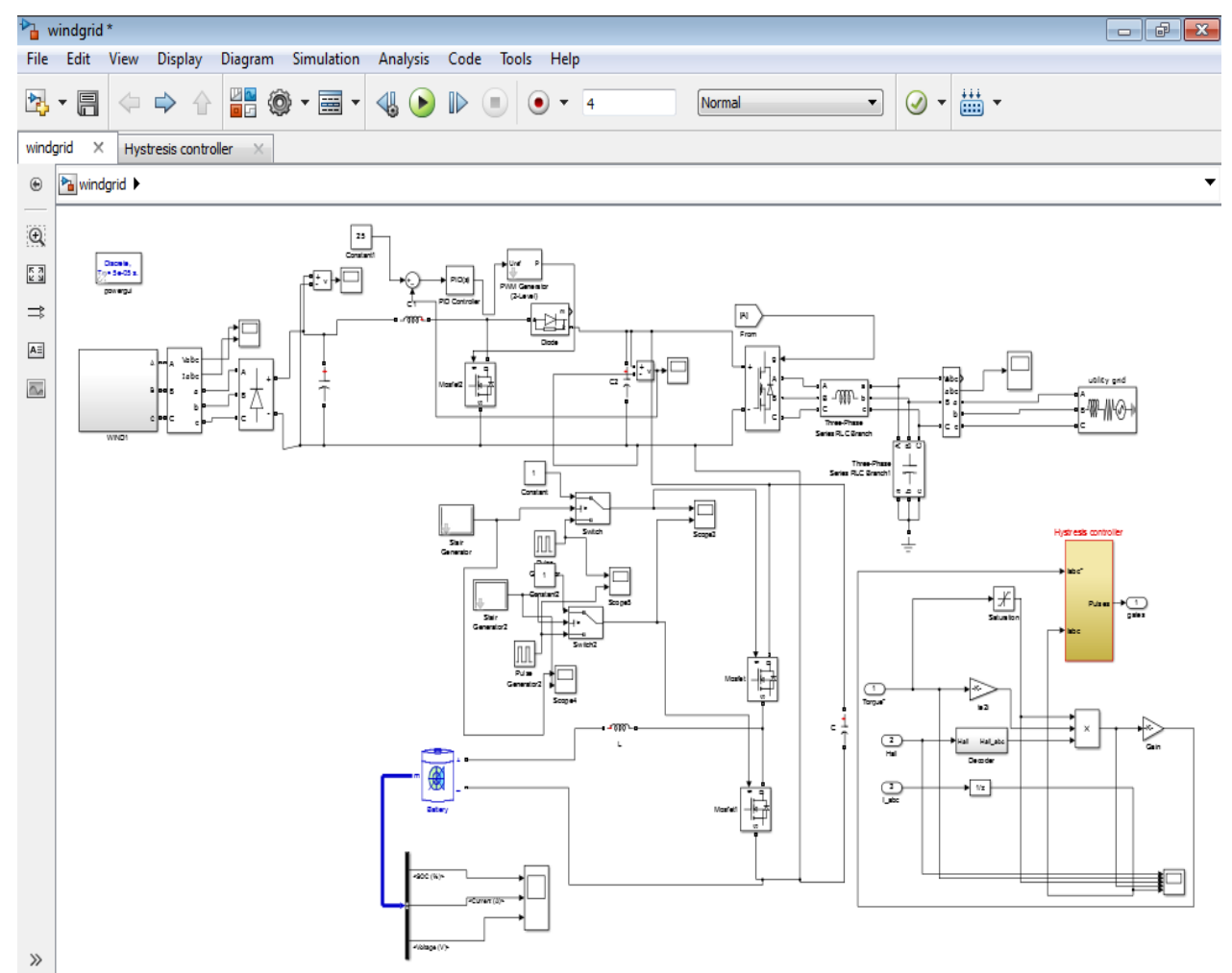

Fig. 3 Simulink model of RAPS system with battery backup

The generated DFIG output voltage to the converter is $25 \mathrm{~V}$ which is shown in Fig. 4.

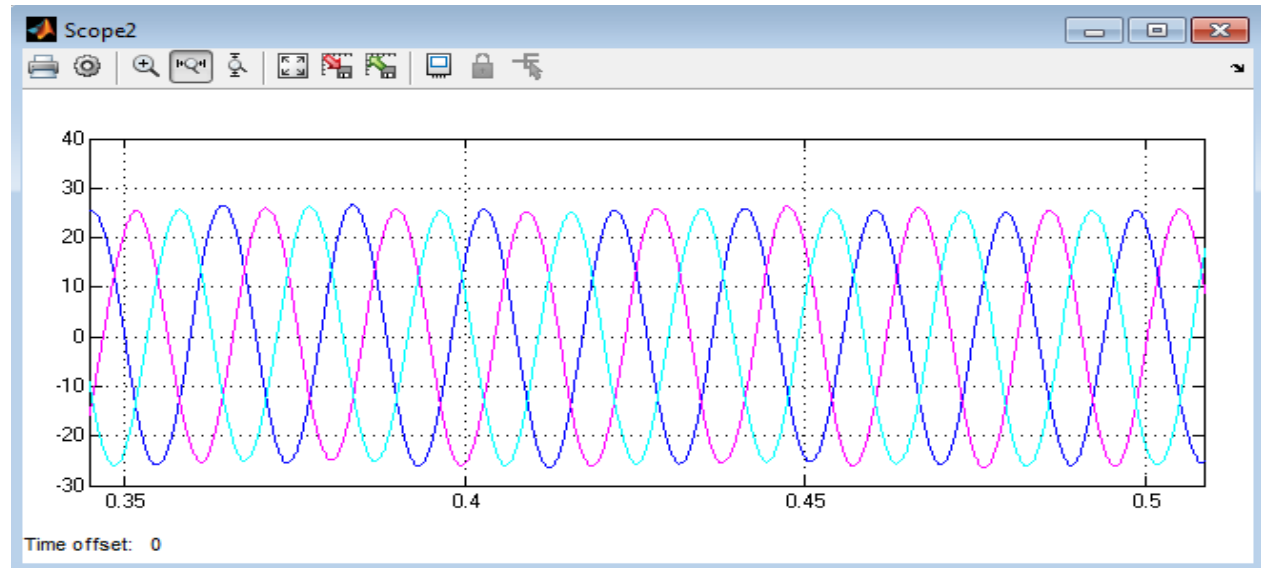

Fig. 4 DFIG output voltage

The generator energy is rectified using rectifier with power diodes and passed through the boost converter to regulate the voltage gain and to maintain the DC link voltage. It is shown in Fig. 5. 


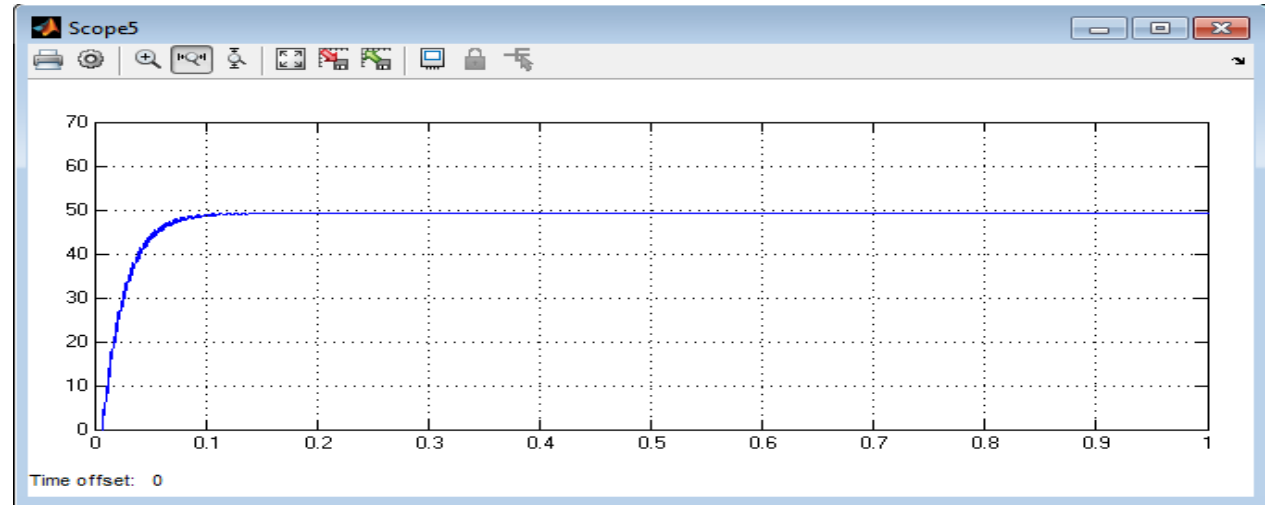

Fig. 5 Obtained DC link voltage

The State Of Charge (SOC) in battery is shown in Fig. 6 during the charge. The battery rated capacity voltage and SOC is about $60 \%$. Thus, the battery sends the voltage continuously to the RAPS.

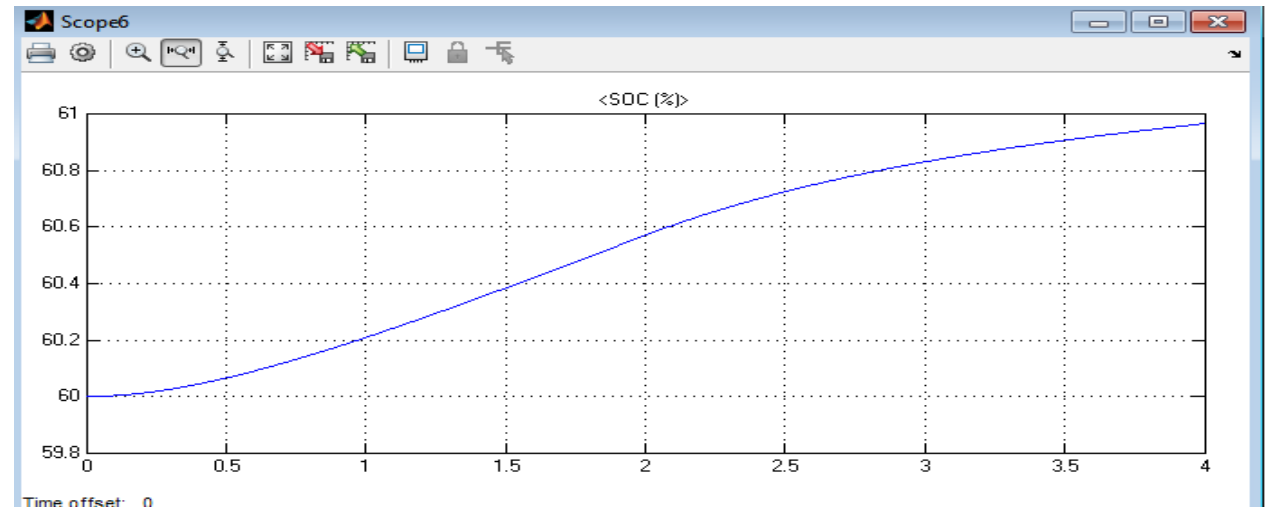

Fig. 6 Battery SOC while charging

The SOC in battery during the discharge is shown in Fig. 7 and the voltage of the battery is shown in Fig. 8 which is obtained from DC link capacitor.

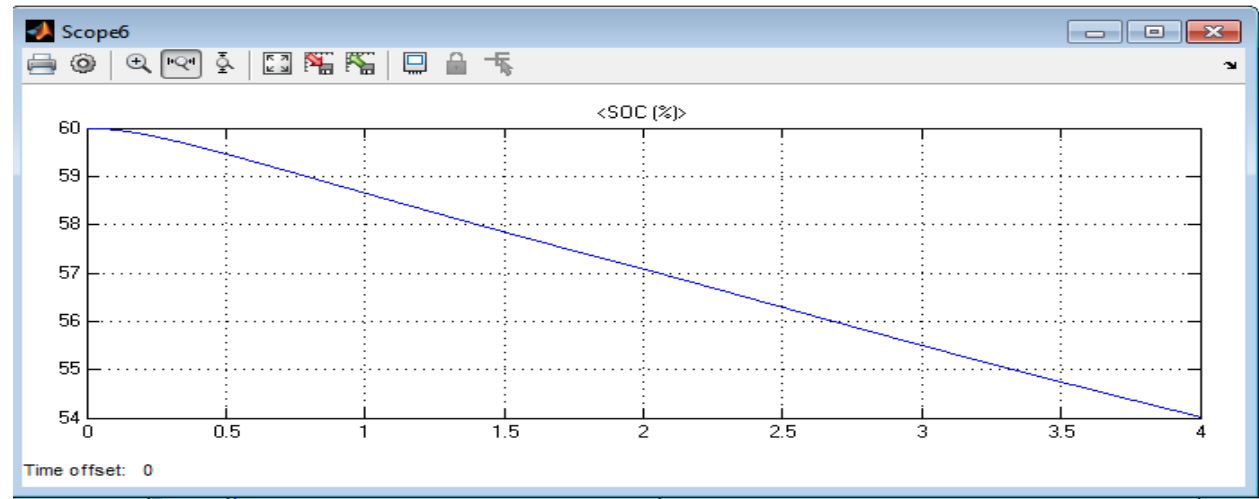

Fig. 7 Battery SOC while discharging 


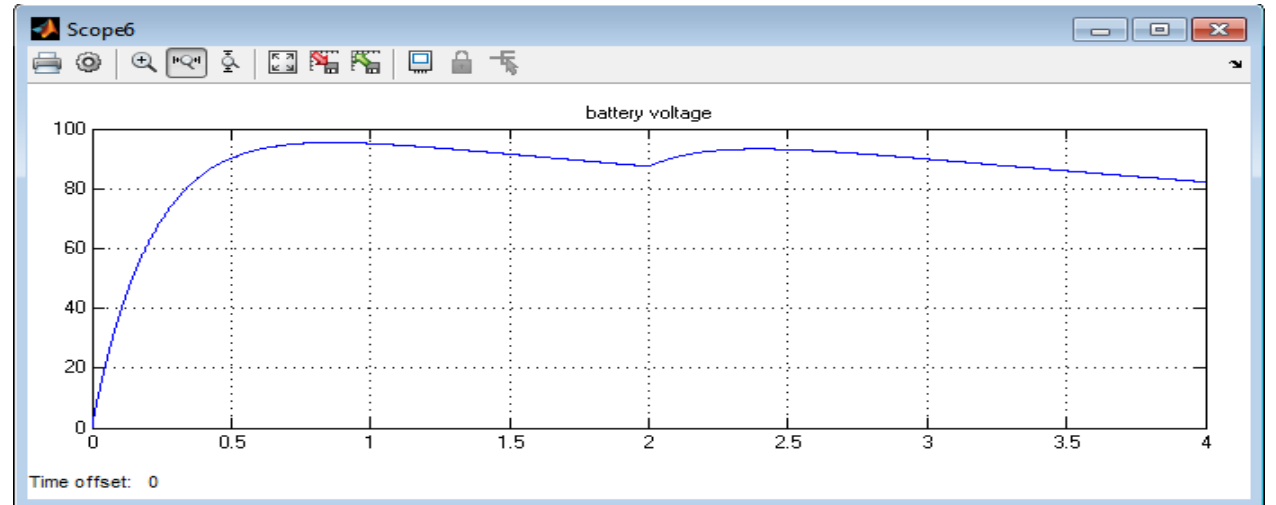

Fig. 8 Battery voltage

Figure 9 shows the output voltage of the RAPS that uses HC to maintain the output voltage. The output voltage is more than $50 \mathrm{v}$.

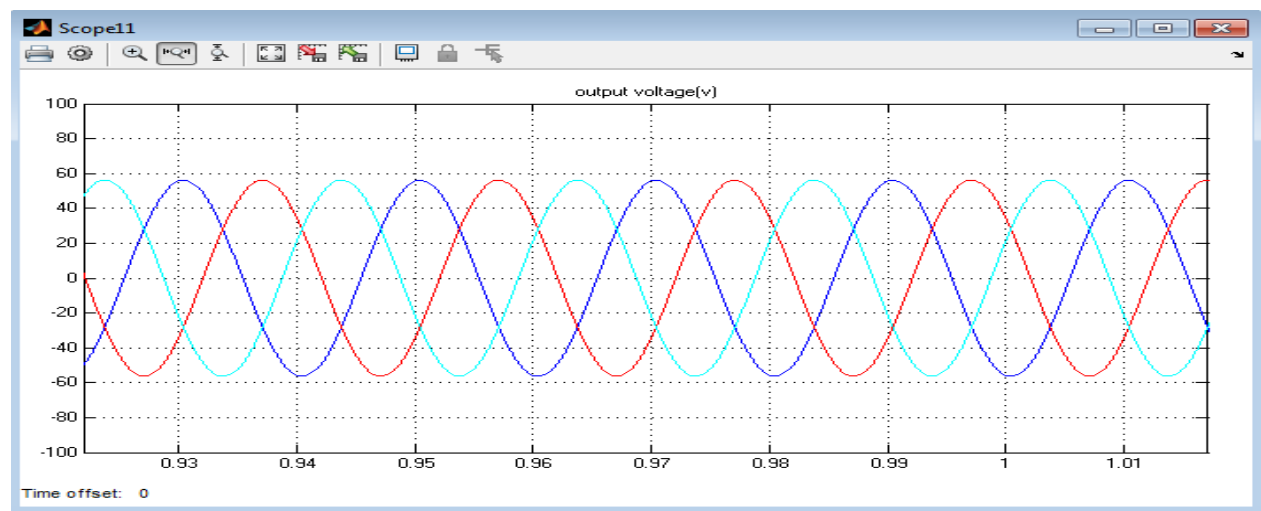

Fig. 9 Output voltage of the system

\section{CONCLUSION}

In this study, an efficient system to provide uninterrupted power to RAPS using HC is designed. The RAPS gets energy from the DFIG generator which generates energy from the wind. Also, a rectification unit is used for rectification process using power diodes. A bidirectional converter is used to store the power in the battery and the charging and discharging of battery is controlled by the SOC. The DC link capacitor voltage is improved by the boost converter and ESS system. Results show that the RAPS provide uninterrupted power by maintaining DC link voltage and better frequency regulation.

\section{REFERENCES}

[1]. M.M. Eissa, "Challenges and novel solution for wide-area protection due to renewable sources integration into smart grid an extensive review", IET Renewable Power Generation, Vol. 12, No. 16, 2018, pp. 1843-53. 
[2]. B. Wang, U. Manandhar, X. Zhang, and A. Ukil, "Deadbeat control for hybrid energy storage systems in DC microgrids", IEEE Transactions on Sustainable Energy, Vol. 10, No.4, 2018, pp. 1867-1877.

[3]. D. Watson, C. Hastie, and M. Rodgers, "Comparing different regulation offerings from a battery in a wind R\&D park", IEEE Transactions on Power Systems, Vol. 33, No. 3, 2017, pp. 2331-8.

[4]. T. Chakraborty, D. Watson, and M. Rodgers, "Automatic generation control using an energy storage system in a wind park", IEEE Transactions on Power Systems, Vol. 33, No. 1, 2017, pp.198-205.

[5]. I.N. Moghaddam, B.H. Chowdhury, and S. Mohajeryami, "Predictive operation and optimal sizing of battery energy storage with high wind energy penetration", IEEE Transactions on Industrial Electronics, Vol.65, No. 8, 2017, pp. 6686-95.

[6]. P. Yu, X. Liu, Y. Zhang, X. Hu, G. Kong, P. Zhao, Y. Cheng, S. Li, X. Zuo, and S. Sun, "Battery-super capacitor hybrid energy storage system for wind power suppression based on the turbulence model of wind speed", The Journal of Engineering, Vol. 2018, No. 17, 2018, pp. 1922-9.

[7]. M. Bello, A. Maitra, R. Dugan, M. McGrail, A. Reid, and R. Rodrigo, "Protection coordination considerations for a highly meshed urban microgrid", IEEE Power \& Energy Society Innovative Smart Grid Technologies Conference, 2018, pp. 1-5.

[8]. B. Housseini, A.F. Okou, and R. Beguenane, "Robust nonlinear controller design for on-grid/off-grid wind energy battery-storage system", IEEE Transactions on Smart Grid, Vol. 9, No. 6, 2017, pp. 5588-98.

[9]. H. Bitaraf, and S. Rahman, "Reducing curtailed wind energy through energy storage and demand response", IEEE Transactions on Sustainable Energy, Vol. 9, No. 1, 2017, pp. 228-36.

[10]. Y.J. Liu, S. Tong, C.P. Chen, and D.J. Li, "Neural controller design-based adaptive control for nonlinear MIMO systems with unknown hysteresis inputs", IEEE transactions on cybernetics, Vol. 46, No. 1, 2015, pp. 9-19.

[11]. J. Peter, M.S. KP, R. Lakshmi, and R. Ramchand, "Nearly Constant Switching Space Vector Based Hysteresis Controller for VSI Fed IM Drive", IEEE Transactions on Industry Applications, Vol. 54, No. 4, 2018, pp. 3360-71.

[12]. X. Mao, Y. Wang, X. Liu, and Y. Guo, "A hybrid feedforward-feedback hysteresis compensator in piezoelectric actuators based on least-squares support vector machine", IEEE Transactions on Industrial Electronics, Vol. 65, No. 7, pp. 5704-11.

[13]. A. Parida, S. Choudhury, and D. Chatterjee, "Microgrid Based Hybrid Energy Co-Operative for Grid-Isolated Remote Rural Village Power Supply for East Coast Zone of India", IEEE Transactions on Sustainable Energy, Vol. 9, No. 3, 2017, pp. 1375-83.

[14]. A. Patel, S. Ghosh, K.A. Folly, "Inter-area oscillation damping with nonsynchronized wide-area power system stabilizer", IET Generation, Transmission \& Distribution, Vol. 12, No. 12, 2018, pp. 3070-8.

[15]. M. Huang, H. Ji, J. Sun, L. Wei, and X. Zha, "Bifurcation-based stability analysis of photovoltaic-battery hybrid power system", IEEE Journal of Emerging and Selected Topics in Power Electronics, Vol. 5, No. 3, 2017,pp. 1055-67. 